\title{
Assessment of the success rate of endodontically treated patients attending outpatient polyclinic
}

\author{
Nazih Shaaban Mustafa ${ }^{1}$, Muhannad Ali Kashmoola ${ }^{1}$, Kais Raad Abdul Majeed ${ }^{2}$, \\ Omar Abdul Jabbar Abdul Qader ${ }^{1}$
}

Correspondence: Dr. Nazih Shaaban Mustafa

Email: drnazih@iium.edu.my

\author{
'Department of Oral Maxillofacial Surgery and Oral \\ Diagnosis, Kulliyyah of Dentistry, International Islamic \\ University Malaysia, Kuantan, Malaysia, \\ ${ }^{2}$ Department of Medical Internal Security Force, Doha, \\ Qatar
}

\section{ABSTRACT}

Objectives: The aim of this study is to determine the success rate of the endodontically treated teeth in patients attending the Polyclinic, Kulliyyah of Dentistry, International Islamic University Malaysia (IIUM), from 2012 to 2015. Materials and Methods: A retrospective study involved endodontically treated teeth of patients attending the Polyclinic, Kulliyyah of Dentistry, IIUM, from 2012 to 2015 . Clinical and radiographic data were recorded and classified as successful or failed, and further analyzed by Fisher's exact test to measure the correlation between the variables using SPSS software version 16.0. Kappa test was used to measure the overall relationship between clinical and radiographic findings. Results: A total of sixty teeth were evaluated clinically and radiographically, the overall success rate was $85 \%(n=51)$. Correlation between the variables showed nonsignificant $(P>0.05)$ in the success rate among age, gender, and race, upper and lower arches and between anterior and posterior teeth at the time of treatment. At postendodontic fixed restorations, the variables showed statistically significant relationship with the success rate $(P<0.05)$. Conclusions: Patients with no signs and symptoms and with no radiographical changes at the the time of clinical examination ,showed the highest percentage of success rate (85\%) of postendodontic fixed restorations. Age, gender, and race have no significant relations with the success rate of endodontically treated teeth.

Key words: Anterior teeth, endodontic, restoration, success rate

\section{INTRODUCTION}

Root canal treatment is one of the procedures to treat the infected pulp of a tooth, with the aim of the treatment is to eliminate the infection and to seal the canal from the future microbial invasion apically and coronally. Other than that, root canal treatment also serves as an elective dental treatment in adjunct to other dental treatments. Root canal treatment is a highly successful procedure if the prognosis is correct and other technical aspects are carefully performed. From the conservative dentistry point of view, it is

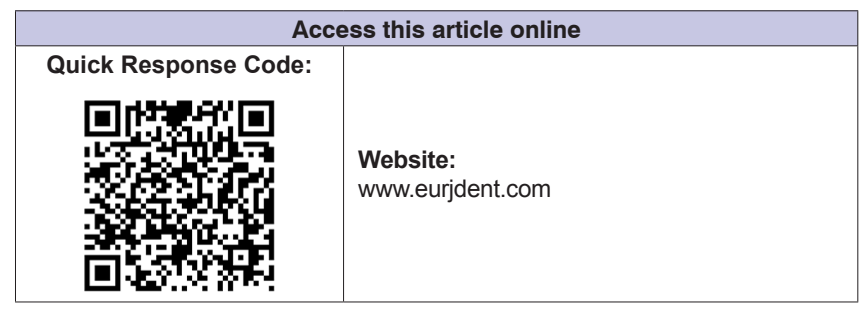

necessary to retain a tooth that would otherwise be extracted. To assess the treatment outcome of the root canal treatment, both clinical and radiographic follow-up reevaluations are essential to determine the success outcome after the endodontic treatment done. The success of the endodontic treatment of the affected teeth is influenced by several factors. Among the factors are age, gender, race, location, and position of the tooth, postendodontic type of restoration and

This is an open access journal, and articles are distributed under the terms of the Creative Commons Attribution-NonCommercial-ShareAlike 4.0 License, which allows others to remix, tweak, and build upon the work non-commercially, as long as appropriate credit is given and the new creations are licensed under the identical terms.

For reprints contact: reprints@medknow.com

How to cite this article: Mustafa NS, Kashmoola MA, Abdul Majeed KR, Abdul Qader OA. Assessment of the success rate of endodontically treated patients attending outpatient polyclinic. Eur J Dent 2018;12:540-5. DOI: 10.4103/ejd.ejd_377_17 
Mustafa, et al:: Assessment of the success rate of endodontically treated patients attending outpatient polyclinic

diagnosis at the time of treatment. Esterla in 2017 mentioned that endodontic treatment outcomes are determined by several factors such as the clinical competency of the clinician..$^{[1]}$ The presence or absence of radiographical changes can be detected by using $\mathrm{CBCT}^{[2]}$ which is a clinicaly useful tool for diagnosis and treatment plan. ${ }^{[3]}$

The rationale for this study is to provide upon the statistical analysis for the success rate of the endodontic treatment by addressing the limitations from the previous researches. Thus, the purpose of this study is to assess the success rate of the endodontically treated teeth in patients attending the Polyclinic, Kulliyyah of Dentistry, International Islamic University Malaysia (IIUM), from February 2012 to June 2015 through clear and definitive definition of successful or failed from the clinical examination assessments and periapical radiographic evaluation; with addition association of several other factors that may contribute to the success of the endodontic treatment.

\section{MATERIALS AND METHODS}

The protocol was approved by the IIUM Research Ethics Committee on July 6, 2015. For the purpose of making comprehend systemic study, the inclusion and exclusion criteria were strictly chosen and followed. Cases from February 2012 to June 2015 were reviewed.

The samples for this study were obtained from the patient's folders with a history of the endodontic treatment performed by the dental students between the year 2012 and 2015 at the Polyclinic, Kulliyyah of Dentistry, IIUM. Documentation from the root canal treatment procedures: radiographic interpretation and clinical examinations and preoperative, intraoperative, and postoperative were assessed.

For this research purposes, six inclusive criteria were defined for the cases to be accepted and assessed. The six criteria are as follows: (1) initial nonsurgical root canal treatment, (2) use of Periapical Index score of one or two to denote success, (3) use of periapical radiograph or cone-beam computed tomography (CBCT) to determine the periapical index value, (4) a minimum follow-up period of 6 months, (5) success or failure will be evaluated per tooth, and (6) age of 18-year-old or older at the time of diagnosis and treatment.

While for the exclusion criteria, eight criteria were defined, which are as follows: (1) failure to use
Periapical Index system, (2) endodontic surgery cases, (3) extractions cases which were not related to the failure of the treatment and retreated cases, (4) patient with underlying systemic diseases, (5) patients who are $<6$ months of follow-up, (6) trauma to the endodontic-treated teeth, (7) Post and core placed, and 8 ) age $<18$ year old at the time of diagnosis and treatment.

In the second part of the study, patients with at least 6-month postoperative interval were called and their endodontically treated teeth were examined clinically and radiographically.

The periapical system developed by Orstavik in $1986^{[4]}$ was used for the radiographic assessment. Using this system, the outcome was rated on the scale from 1 to 5 , and the successful case only denoted to score 1 or 2 only. The periapical system developed by Ostravik et al. (1986) are as follows: (1) Score 1 which indicates periapical destruction of bone is almost definitely not present, (2) Score 2 which indicates periapical destruction of bone is probably not present, (3) Score 3 which indicates periapical destruction of bone is unclear from radiographic assessment, (4) Score 4 which indicates destruction of bone is probably present, and (5) Score 5 which indicates periapical destruction of bone is almost definitely present.

The clinical examination and assessment of the outcomes were categorized into two: the presence or absence of signs and symptoms, which donated as a success or failure of the endodontic treatment. The signs and symptoms are as follows: (a) loss of function on respected treated teeth, (b) tenderness on palpation and percussion, (c) subjective discomfort, (d) mobility, and (e) present of the sinus tract.

In case that the treated tooth been extracted after the endodontic treatment was done, this is the reason, why the tooth went for extraction was determined. The tooth that had been extracted due to the failure of the root canal treatment was assessed in the study, while the tooth that had been extracted other than failure was excluded from the study of the research.

For the measurements of evaluated data, standardization of the evaluation criteria was done before analyzing the cases. This is to ensure that the results obtained were from the same evaluation methods and assessments. In between, when there was disagreement about the outcome, the disagreement was resolved through a discussion till the agreement reached. 
Regarding statistical analysis, the dependent variables were dichotomous outcomes; success or failed. First, a univariate description represented by the percentage frequencies was generated to see the pattern of materials being studied. Second, correlations between the outcomes and the variables were assessed through bivariate description (Chi-square or Fisher's exact test) at the 95\% level of confidence; this is to identify any possibility linking of prognostic factors. The statistical analysis was coded into SPSS version 16.0 for Windows (Chicago, IL, USA). Kappa test at Polyclinic, Kulliyyah of Dentistry, IIUM Kuantan Pahang Malaysia was used to measure the overall relationship between clinical and radiographic findings.

\section{RESULTS}

A total of 311 teeth were assessed and examined in this study. Out of 311 teeth, 251 teeth $(80.71 \%)$ were excluded due to (1) 118 teeth samples (47.01\%) cannot be assessed due to the loss of contact number, patients refused to come and patients moved to other city; (2) 64 teeth $(25.50 \%)$ went for post and core treatment; (3) 19 teeth $(7.57 \%)$ were not completed cases; (4) 17 teeth $(6.77 \%)$ were $>6$ months treated; (5) 13 teeth $(5.18 \%)$ were root canal retreated cases; (6) 7 teeth $(2.79 \%)$ without intraoral periapical radiograph; (7) 5 teeth $(1.99 \%)$ were extracted with nonfailure root canal treatment related; (8) 4 teeth $(1.59 \%)$ excluded due to pregnancy status; and (9) 4 teeth $(1.59 \%)$ excluded due to medically compromised status of the patients.

Of the 311 teeth, the final samples of $60(n=60)(19.29 \%)$ teeth were evaluated into the inclusion criteria. At the end of the study, a total of $51(n=51)$ teeth $(85 \%)$ were retained in the oral cavity and were classified as definitely successful, while another $9(n=9)$ teeth $(15 \%)$ were extracted and were classified as failure.

According to the variables or factors set in the study, of the 60 teeth assessed in the study, $15(n=15)$ teeth $(25 \%)$ were from the age ranges of 20-30-year-olds, $10(n=10)$ teeth $(16.7 \%)$ from the age ranges of $31-40$ year olds, $18(n=18)$ teeth $(30 \%)$ from the age ranges of 41-50-year-olds, and $17(n=17)$ teeth $(28.3 \%)$ from the age ranges of 50 -year-olds and above. $46.67 \%(n=28)$ teeth were from male patients, whereas another $53.33 \%(n=32)$ teeth from female patients.

Based on races assessment, $53(n=53)$ teeth equivalent to $88.33 \%$ came from the Malay population, while the rest $7(n=7)$ teeth $(11.67 \%)$ came from the Chinese populations. From the study, no sample is available from the Indian and other races.

Of the total, $23.33 \%(n=14)$ teeth were restored with temporary restoration, $53.33 \%(n=32)$ teeth were restored with semi-permanent restoration, and remaining $23.33 \%(n=14)$ teeth were went for fixed prosthesis restoration.

Almost $66.67 \%(n=40)$ teeth of the total sample were from the upper arch and another $33.33 \%(n=20)$ teeth from the lower arch.

Fifty percent $(n=30)$ teeth were from the anterior teeth and $50 \%(n=30)$ teeth were from the posterior teeth.

Based on the diagnosis at the treatment time, $20 \%(n=12)$ teeth were diagnosed with symptomatic irreversible pulpitis, $20 \%(n=12)$ were diagnosed with necrotic pulp with periapical abscess, $20 \%(n=12)$ teeth were diagnosed with pulp necrotic, $11.67 \%(n=7)$ teeth were diagnosed with pulp necrotic with symptomatic apical periodontitis, $21.67 \%(n=13)$ teeth were diagnosed with pulp necrotic with asymptomatic apical periodontitis, and $6.67 \%(n=4)$ teeth were diagnosed with asymptomatic irreversible pulpitis.

From the result obtained, Cohen's kappa coefficient was used to measure the interrater agreement overall relationship between the clinical examinations and periapical radiograph assessments. From the calculation, number of observed agreements is 56 (93.33\% of the observations) and number of agreements expected by chance is 44.7 (74.50\% of the observations); and hence, the kappa $=0.739$ with the standard error of 0.124 and $95 \%$ confidence interval, which indicates the strength of agreement is good as shown in Table 1.

Thus, the overall success rate combining clinical and radiographic assessments gives $85 \%(n=51)$ teeth that were rated as successful endodontic treatment, while another $15 \%(n=9)$ teeth were rated as failure.

In term of correlations between the success rate and the age groups, the results showed that at the $95 \%$ significance interval, with degree of freedom 9 and the Chi-square statistic of $10.8836, P$ value was found to be 0.284 . The result is not statistically significant at $P<0.05$.

In terms of the correlations between the success rate and the gender, the results showed that at the $95 \%$ significance interval, with degree of freedom 3 and 
the Chi-square statistic of $2.889, P$ value was found to be 0.409 . The result is not statistically significant at $P<0.05$.

With regard to the success rate and the races, the results showed that at the $95 \%$ significance interval, with degree of freedom 3 and the Chi-square statistic of 3.264, $P=0.353$. The result is not significant at $P<0.05$.

On the subject of the correlations between the success rate and the type of restoration done after the endodontic treatment done, the results showed that at the $95 \%$ significance interval, with degree of freedom 6 and the Chi-square statistic of $13.54, P=0.035$. The result is statistically significant at $P<0.05$.

In terms of correlations between the success rate and the arches, the results showed that at the 95\% significance interval, with degree of freedom 3 and Chi-square statistic of 2.648, $P=0.449$. The result is not statistically significant at $P<0.05$.

About the correlations between the success rate and the position of the tooth, anterior or posterior, the results showed that at the $95 \%$ significance interval, with degree of freedom 3 and Chi-square statistic is 2.327 , the $P=0.507$. The result is not statistically significant at $P<0.05$.

Regarding the success rate and the diagnosis at the time of treatment, the results showed that at the $95 \%$ significance interval, with degree of freedom 15 and Chi-square statistic is 11.808 , the $P=0.694$. The result is not statistically significant at $P<0.05$.

\section{DISCUSSION}

In this study, intraoral periapical radiograph was used to screen, diagnose, and evaluate the endodontic cases instead of CBCT, even CBCT can be used due to its accuracy and sensitivity for the detection of periapical changes. The reliability of radiographic interpretations is agreed by the study done by Goldman et al., ${ }^{[5]}$ in which they agreed between $72 \%$ and to $88 \%$, as in our study, the $74.50 \%$ agreement achieved. Thus, as also wrote by Chugal et al. in 2017, radiographic assessment is an important as an aid tool for the prognosis of endodontic treatment. ${ }^{[6]}$ The uses of CBCT was highly recommended by Estrela et al., ${ }^{[2]}$ as they claimed that the images produced on CBCT describes the actual, correct, multidimensional of existence, and absence or healing of apical periodontitis. The results from the study (85\%) showed a high success rate of endodontic treatment. This is in agreement with the observations of Imura et al., ${ }^{[7]}$ Friedman and Mor, ${ }^{[8]}$ Swartz et al.,$^{[9]}$ and Barbakow et al. ${ }^{[10]}$ who found that $91.5 \%, 81 \%, 89.66 \%$, and $87.4 \%$, respectively, of successful evaluation. Then, even though at the $70 \%$ of successful outcome, slightly below than the other studies, which indicates "good," Meanwhile, a study done by the Salehrabi and Rotstein also reported $97 \%$ success rate. ${ }^{[11]}$ Similar to a study conducted as the current one, Travassos et al. in their results concluded the success rate of $82.9 \% .^{[12]}$ These mean that, in agreement with previous studies, the endodontic treated tooth is an expected procedure with an outstanding high success rate.

The result success rate of this study in terms of age groups showed no correlations. The result is agreed with the study done by Friedman and Mor, ${ }^{[8]}$ which stated this aspect were fairly minute and insignificant $(<10 \%)$. In other study, Eriksen et al. ${ }^{[13]}$ and Sjogren et al. ${ }^{[14]}$ concluded that age had no influence on the success of the endodontic treatment. However, the result contradicts with the study done by Imura et al. in 2007. ${ }^{[7]}$ Their findings showed statistically significant correlations between age group and success rate (50-59 age group with the highest healed rate). This finding also was reported in Smith et al. (2007) that claimed age was strongly significant in outcome of success rate.

From the result, it is apparent that the success rate is not related to gender. This is agreed in the study done by Liang et al., ${ }^{[15]}$ Travassos et al. ${ }^{[16]}$ and Dammaschke et al., ${ }^{[17]}$ in which, their results showed no significant in term of gender to the outcome of success rate.

In terms of correlation between the race and outcome of the endodontic treatment, the result is not statistically significant.

From the type of restoration done after the treatment of endodontic, it is significantly influenced the outcome of the success rate. In 2007, Stavropulou and Koidis in their study, show a conclusion that root-treated teeth that restored with crowns have a long-term survival rate of about 10 years, and they claimed that direct restoration endodontically treated teeth do manage to survive for only a short time. ${ }^{[18]}$ Two years before that in 2005, Nagasiri and Chitmongkulsuk stated in their study, in which for the $1^{\text {st }} 2$ years after the obturation, if the teeth were crowned, the success rate are from $96 \%$ in the $1^{\text {st }}$ year and $88 \%$ in the $2^{\text {nd }}$ year. ${ }^{[19]}$ Salehrabi and Rostein had compared that 4.8 -fold for anterior 
Mustafa, et al.: Assessment of the success rate of endodontically treated patients attending outpatient polyclinic

\begin{tabular}{|c|c|c|c|c|}
\hline \multicolumn{5}{|c|}{ Clinical results $\times$ radiographic results cross tabulation } \\
\hline \multirow{2}{*}{$\begin{array}{l}\text { Clinical } \\
\text { results }\end{array}$} & & \multicolumn{2}{|c|}{ Radiographic results } & \multirow[t]{2}{*}{ Total } \\
\hline & & Success & Failure & \\
\hline \multirow[t]{3}{*}{ Success } & Count & 49 & 2 & 51 \\
\hline & Percentage within clinical results & 96.1 & 3.9 & 100.0 \\
\hline & Percentage within radiographic results & 96.1 & 22.2 & 85.0 \\
\hline \multirow[t]{3}{*}{ Failure } & Count & 2 & 7 & 9 \\
\hline & Percentage within clinical results & 22.2 & 77.8 & 100.0 \\
\hline & Percentage within radiographic results & 3.9 & 77.8 & 15.0 \\
\hline \multirow[t]{3}{*}{ Total } & Count & 51 & 9 & 60 \\
\hline & Percentage within clinical results & 85.0 & 15.0 & 100.0 \\
\hline & Percentage within radiographic results & 100.0 & 100.0 & 100.0 \\
\hline
\end{tabular}

teeth, 5.8-fold for premolars, and 6.2-fold for molars for the risk of extraction for teeth with not crowning after the endodontic treatment. ${ }^{[1]}$ Aquilino and Caplan in 2002, mentioned in the result of their study that the risk of lost at 6 times higher rate in comparison endodontically and crowned teeth. ${ }^{[20]}$ According to Peak et al., a success treatment of endodontic case will be determined through the complete elimination and sealing of the microorganisms from the root canal system; both through restoration type coronally and obturation apically. ${ }^{[21]}$ This is supported by previous studies done by again Aquilino and Caplan. in 2002, in which they stated that long-term survival of root-treated tooth is strongly associated with crown placement. ${ }^{[20]}$ However, only a study published in 1967 done by Bender and Seltzer. reported that crowned endodontically treated teeth have a greater tendency for failure compared to noncrowned teeth. A complete sealing of the root canal will promote and maintain the health of the tooth. ${ }^{[22]}$

With regard to the relationship between the success rate and the location and position of teeth either in the upper or lower arch and anteriorly or posteriorly, results showed that there were no significant differences between both arches. However, Imura et al. wrapped up in the study that anterior make known a significantly higher percentage of success measure up to premolars and molars. ${ }^{[7]}$ In 2004, Salehrabi and Rostein in their study concluded that the highest success rate for the endodontically treated teeth was from the anterior teeth, comprising $97.43 \%$ compared to premolars $(97.32 \%)$ and molars (96.89\%). ${ }^{[11]}$ Meanwhile, previously, Peak et al. specifically did mention that anterior maxillary teeth have $96 \%$ of success rate compared to other teeth types. ${ }^{[21]}$

Regarding the relationship of the diagnosis at the treatment time with the outcome of the success rate, from this study, there is no correlation. But in a study conducted by Friedman and Mor, those teeth that involved with apical periodontitis showed lower success rate compared to only pulp necrotic involved tooth. ${ }^{[23]}$

This is study is important in giving impact to formulate the prognosis of treatment planning if long-term tooth retention with full functional. In addition, all these factors also give affect in planning the treatment plan. With this, it is hope that this study will help in providing more statistically adequate and accurate evidence-based data for the professions in determining the success rate of the endodontic treatment.

\section{CONCLUSIONS}

The overall success rate of endodontically treated teeth in this study was $85 \%$. The significant factor that contributed to the success rate was the type of restoration after the obturation. The strong correlation between the types of restoration may significantly enhance the long-term survival rate of the endodontically treated teeth. This is important in informing patient about the postendodontic treatment restoration types available to aid in long retention of functionally teeth in oral cavity. The results of this study also important in managing patients, it aids in giving predictable forecast to what will be expected after the treatment.

\section{Financial support and sponsorship \\ Nil.}

\section{Conflicts of interest}

There are no conflicts of interest.

\section{REFERENCES}

1. Estrela C, Pécora JD, Estrela CR, Guedes OA, Silva BS, Soares CJ, et al. 
Common operative procedural errors and clinical factors associated with root canal treatment. Braz Dent J 2017;28:179-90.

2. Estrela C, Holland R, Estrela CR, Alencar AH, Sousa-Neto MD, Pécora JD, et al. Characterization of successful root canal treatment. Braz Dent J 2014;25:3-11.

3. Silva EJ, Nejaim Y, Silva AI, Haiter-Neto F, Zaia AA, Cohenca N, et al. Evaluation of root canal configuration of maxillary molars in a Brazilian population using cone-beam computed tomographic imaging: An in vivo study. J Endod 2014;40:173-6.

4. Orstavik D, Kerekes K, Eriksen HM. The periapical index: A scoring system for radiographic assessment of apical periodontitis. Endod Dent Traumatol 1986;2:20-34.

5. Goldman M, Pearson AH, Darzenta N. Reliability of radiographic interpretations. Oral Surg Oral Med Oral Pathol 1974;38:287-93.

6. Chugal N, Mallya SM, Kahler B, Lin LM. Endodontic treatment outcomes. Dent Clin North Am 2017;61:59-80.

7. Imura N, Pinheiro ET, Gomes BP, Zaia AA, Ferraz CC, Souza-Filho FJ, et al. The outcome of endodontic treatment: A retrospective study of 2000 cases performed by a specialist. J Endod 2007;33:1278-82.

8. Friedman S, Mor C. The success of endodontic therapy - Healing and functionality. J Calif Dent Assoc 2004;32:493-503.

9. Swartz DB, Skidmore AE, Griffin JA Jr. Twenty years of endodontic success and failure. J Endod 1983;9:198-202.

10. Barbakow FH, Cleaton-Jones P, Friedman D. An evaluation of 566 cases of root canal therapy in general dental practice 2. Postoperative observations. J Endod 1980;6:485-9.

11. Salehrabi R, Rotstein I. Endodontic treatment outcomes in a large patient population in the USA: An epidemiological study. J Endod 2004;30:846-50.

12. Travassos RM, Caldas Ade F, de Albuquerque DS. Cohort study of endodontic therapy success. Braz Dent J 2003;14:109-13.

13. Eriksen HM, Kirkevang LL, Petersson K. Endodontic epidemiology and treatment outcome: General considerations. Endod Top 2002;2:1-9.

14. Sjogren U, Hagglund B, Sundqvist G, Wing K. Factors affecting the long-term results of endodontic treatment. J Endod 1990;16:498-504.

15. Liang YH, Li G, Wesselink PR, Wu MK. Endodontic outcome predictors identified with periapical radiographs and cone-beam computed tomography scans. J Endod 2011;37:326-31.

16. Siqueira JF Jr., Sen BH. Fungi in endodontic infections. Oral Surg Oral Med Oral Pathol Oral Radiol Endod 2004;97:632-41.

17. Dammaschke T, Steven D, Kaup M, Ott KH. Long-term survival of root-canal-treated teeth: A retrospective study over 10 years. J Endod 2003;29:638-43.

18. Stavropoulou AF, Koidis PT. A systematic review of single crowns on endodontically treated teeth. J Dent 2007;35:761-7.

19. Nagasiri R, Chitmongkolsuk S. Long-term survival of endodontically treated molars without crown coverage: A retrospective cohort study. J Prosthet Dent 2005;93:164-70.

20. Aquilino SA, Caplan DJ. Relationship between crown placement and the survival of endodontically treated teeth. J Prosthet Dent 2002;87:256-63.

21. Peak JD, Hayes SJ, Bryant ST, Dummer PM. The outcome of root canal treatment. A retrospective study within the armed forces (Royal Air Force). Br Dent J 2001;190:140-4.

22. Bender IB, Seltzer S, Soltanoff W. Endodontic success - A reappraisal of criteria 1. Oral Surg Oral Med Oral Pathol 1966;22:780-9.

23. Dugas NN, Lawrence HP, Teplitsky PE, Pharoah MJ, Friedman S. Periapical health and treatment quality assessment of root-filled teeth in two Canadian populations. Int Endod J 2003;36:181-92. 